\title{
Ennustamisega seotud motiivid regilauludes
}

\section{Aado Lintrop}

Millega võiks õigustada arutlemist regilaulude mütoloogiliste motiivide üle?

Ühest küljest on selleks suurenenud huvi regilaulu kui sellise vastu üldse, mida näitas kas või viimase selleteemalise konverentsi rahvast täis saal. Teisest küljest on vastavaid käsitlusi suhteliselt vähe ja needki (peamiselt Soome teadlaste töödes leiduvad) püüavad näidata pigem ühe või teise motiivi algupära ja sünniaega kui vaadelda neid tähendusi muutvate poeetiliste väljendustena muutlikul usundilisel taustal. Paradoksaalsel kombel avab just loobumine regilaulu motiivide käsitamisest esivanemate kindla tähendusega sõnumitena tee nende tähenduslikkuse mõistmiseks, luues eeldused nende potentsiaalse mitmemõttelisuse ja polüfunktsionaalsuse möönmisele. Alles siis, kui näeme motiive selliste tekstidetailidena, võime hakata küsima nende kasutamis- ja ümbertegemisvõimaluste kohta.

Kas on üldse mõtet rääkida motiividest?

Kuna võime regilaulude motiive pidada laulude koostamise kognitiivseteks üksusteks, on selge, et need pole olnud ega saa olema regilaulu uurimise "ideaalsed tüübid", mille piiritlemine ja kirjeldamine võimaldaks öelda "kogu tõe" nii tekstide kui ka esituste kohta. Vastavalt vajadustele tunnetas laulik motiive kas suuremate või väiksemate meetrilise allstruktuuriga sõnakooslustena. Minu arvates on just see "vastavalt vajadusele" kiviks, mille otsa paratamatult komistab iga teooria, mis tahab sedalaadi tekstiloomise komponente liigitada ja mõõta. Nagu kirjanduslikud ja rahvaluuležanrid, nii on ka motiivid, teemad ja vormelid praktilistest vajadustest lähtuva liigitussüsteemi loomiseks kasutatavad põhimõtted, mida B. Croce võrdles raamatute korrastamisega formaadi, autorite, teemade jt tunnuste või omaduste järgi. Ta lisas:

Mida te aga kostaksite selle peale, kui keegi asuks tõemeeli uurima, missugused kirjanduslikud seaduspärasused avalduvad teostes, mis kuuluvad rubriiki varia või miscellanea, Aldo Manuzio või Bodoni sarja, A- või B-riiulile - neisse täiesti su-

http://haldjas.folklore.ee/tagused/nr24/lintrop.pdf 
Aado Lintrop

valistesse rühmitustesse, mis tulenevad lihtsalt praktilisest vajadusest? (Croce 1998: 70).

Asi pole siiski ainult loogilises võimatuses tuletada mõistest väljendust, leida asendajast asendatava seadusi (Croce 1998: 67), vaid asjaolus, et isegi juhul, kui rahvaluule esitajad ise kasutasid tekstide loomiseks analüütiliste mõistetena piiritletuile mingilgi määral sarnanevaid üksusi, ei suuda ükski mudel neid piisavalt hõlmata. Sellepärast ei käsitlegi ma motiive kui kindlaid struktuuriosi, mida tekstide loojad ja esitajad tajuvad ühtmoodi. Minu arvates on motiivid kultuurilised liigituskategooriad jadalistena tunnetatavate tegevuste, toimingute, olukordade ja nähtuste mõtteliselt sarnaste lõikude ühendamiseks. Sellisel kujul on need vahendid mõtlemise ja arutlemise organiseerimiseks ning sellest lähtuvalt on mõtet neist ka rääkida.

Mis siis võiks olla aluseks väitele, et regilaulude motiivid võivad sisaldada tähendusi, mida nende kasutajad ei teadvusta?

Teoreetiliselt on võimatu näidata, et regilaulud on eksisteerinud kogu aja muutumatul kujul. Vastupidi, isegi pealiskaudne tekstidega tutvumine veenab, et laulude koostisosi on kasutatud erinevates tähendustes ja funktsioonides. Tegelikult on mitmemõttelisus poeetilisele väljendusviisile olemuslik ning legaliseerib ühtede ja samade sõnakoosluste (siinses kontekstis motiivide) tõlgendamise nii poeetiliste kujunditena kui ka sõnasõnaliselt. Mõlemal juhul on võimalik rohkem kui üks tõlgendus. Kui eeldame, et lauludele oli omane ka teatud funktsioon (mis on igati mõistuspärane oletus), siis on selge, et funktsioon ja tähendus pidid olema mingil määral seotud. Antud juhul pole oluline, kas funktsiooni muutus tingis tähenduse muutumise või vastupidi või olid võimalikud mõlema suunaga protsessid. Oluline on, et mingis funktsioonis ühe kindla tähendusega motiiv võis teises funktsioonis omandada poeetilise kujundi tähenduslikkuse.

Miks just ennustamisega seotud motiivid?

Kui vaatleme eri rahvaste rituaalset repertuaari, moodustavad selles lõviosa kogukonna või selle üksikliikmete tuleviku stabiliseerimist teenivad tekstid, mis ühelt poolt eeldavad usku sellesse, et tulevasi sündmusi on võimalik ette näha ja mõjutada, teiselt poolt aga nõuavad selleks vastava informatsiooni hankimist. Pole siis ime, et paljud sedalaadi tekstid seostuvad kas sisult või funktsioonilt ennustamisega. Käesolevas artiklis mõistan ennustamise all mitte ai- 
nult toiminguid kellegi või millegi tulevikku puudutavate seikade kohta ütluste tegemiseks, vaid ükskõik mille kohta informatsiooni hankimist üleloomuliku sfääri abil või kaudu.

Regilaulude oletatavate ennustamisega seotud motiivide selgitamiseks vaatlen neid Põhja-Euraasia rahvaste usundite taustal. Selles kontekstis kujutatakse tuleviku vm kohta informatsiooni hankimist sageli nägemusliku rännakuna kuhugi, kus on võimalik suhelda seda valdavate üleloomulike olenditega, kusjuures teavet ei edastata tavaliselt otsesõnaliselt, vaid sümboolsel kujul, mille tähendus tuleb asjaosalisel ära arvata või mõistatada. Näiteks jutustab nganassaani šamaan Semjon Momde:

Kui kojale lähenesime, vaatas sellest välja inimene, kes hoidis kätt kuklal. See oli seitsme patsiga naine [---] Kaaslane opetas mind: "Sa ütle, et see on selle jõe perenaine." Tema poole vaatamata kordasin neid sõnu. Astusime kotta. Seal istus tüdruk [---] Mu kaaslane istus ta kõrvale ja palus, et tüdruk talle patsi pähe punuks. Tüdruk ei vasta midagi, kaaslane muudkui palub. Teisel pool on veel kaks tüdrukut. Räägime omavahel: "Läheme ja istume hoopis nende juurde, küll nemad meile patsid pähe punuvad." Need on šamaanide esiemad, punuvad nende juuksed enne tagasipöördumist patsi. Esimene naine küsib: "Kas külalised jäävad öömajale?" "Jah," vastame meie. "Kui nii, siis annan öömajalistele mõistatuse mõistatada." Üks mu kaaslastest ütleb: "Meie ei oska midagi mõistatada. Samojeedi poeg tõi meid siia. Las tema mõistatab." Ütlesin: "Mida ma mõistatan? Olgu pealegi, teen proovi. Jõe kaldal vedelev puutüvi pole harilik puu. On ju nii elavatel kui surnutel ruhed. Ainult et surnu ruheks on narta. ${ }^{1}$ See puutüvi on selleks, et inimesed sellest ongeritvu teeksid ja kala pü̈̈aksid." "Õige!” kostis naine... (Popov 1984: 105).

Antud näitest selgub, et puutüve tõlgendatakse kui head ennet, mitte kui surma märki. (Võimalik mõttekäik on selline: puutüvi = materjal ruhe õõnestamiseks $\neq$ surnu sõiduk, sest surnu jäetakse matusepaika kombekohaselt nartale asetatuna, järelikult puutüvi $=$ materjal elavate tarbeks.)

Teiseks laialt levinud ennustusviisiks on mitmesuguste esemete kasutamine, mille liikumist, asendit või kuju võetakse kui ennet või mille abil tekitatakse visioone. Ka sel juhul on meil tege- 
Aado Lintrop

mist sümboolsete tähenduste ja nende tõlgendamisega. On loomulik eeldada, et sümbolite tõlgendamine võib aja jooksul muutuda. Ent motiivi tuumas asuva sümboli tähenduse muutus toob paratamatult kaasa kogu motiivi tähenduse muutumise. Tõenäoliselt pole kunagi võimalik üht või teist motiivi seostada täiesti kindlalt ennustamisega. Kõik see, mida nüüd ja edaspidi võime teha, on osutamine nende võimalikele seostele sedalaadi toimingute ja uskumustega. Järgnev ongi selline katse, milles esitatav ennustusviiside loetelu ei pretendeeri kõikehõlmavusele.

\section{Ennustamine üleloomuliku sfääriga kontakteerumise või seal käimise kaudu}

Regilauludele on iseloomulik, et sageli käivitub sündmustik minategelase kusagil käimisest. Sageli kaasneb käimisega mingi sõnumi saamine või ilmutuse (nägemuse) nägemine. Setus on selline skeem andnud hulga erinevaid laulutüüpe. Venna sõjaloos näiteks on metsas kohatud linnud need, kelle "kirjad" ütlevad, et venna kord on sõtta minna.

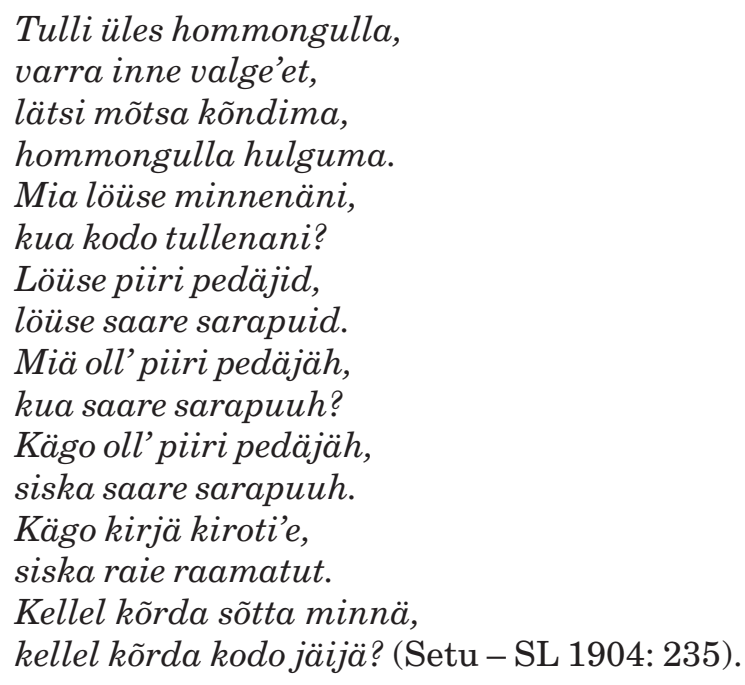

Tulli üles hommongulla, varra inne valge'et, lätsi mõtsa kõndima, hommongulla hulguma. Mia lö̈̈se minnenäni, kua kodo tullenani? Lö̈̈se piiri pedäjid, löüse saare sarapuid. Miä oll' piiri pedäjäh, kua saare sarapuuh? Kägo oll' piiri pedäjäh, siska saare sarapuuh. Kägo kirjä kiroti'e, siska raie raamatut. Kellel kõrda sõtta minnä, kellel kõrda kodo jäijä? (Setu - SL 1904: 235).

Sama laulutüübi Põhja-Eesti tekstis käib minategelane (õde) Käbikülas ja Ubasalos, mis ilmselt pole reaalselt eksisteerivad paigad: 
Käisin ma Käbikülassa, hulkusin Ubasalose hummalaida otsimaies. Senna ma sõle unestin, vaskeaiusse vahetin.

Sõda tousis sõlestaia, vaeno vaskiaiustagi (Haljala - VK 1989: 335).

Kuigi sõja sõlest tõusmine võib tähendada ka sõle abil ennustamist, on selles laulus rõhutatud just kusagil käimist. Madis Arukask on avaldanud oma Venna sõjalugu käsitlevas magistritöös arvamust, et laulus esinevad sedalaadi kohad võivad osutada teispoolsele sfäärile või sinna viivatele paikadele (vt Arukask 1998: 4647). Sõda aga ei pruugi mõnedes setu lauludes tähendada mitte niivõrd sündmust, kuivõrd mingit mütoloogilist substantsi, stiihilist jõudu (Arukask 1998: 40-43).

Algusvormeliga Lähme loojale loole motiivide liitumisel on mingi järjekindlus. Ükskõik, kas järgneb Kulla põlemine või Kotkas kaare alt, ikka jõutakse välja nelja (vahel ka kolme) kuduva neiuni, kellest üks nutab noort meest:

Lähme loojale loole,

Marinulle heinamaale,

looja loogu' vottamaie.

Niidin kaare, niidin kaks,

mis ma leidsin kaare alt?

Juri leidsin kaare alt.

Mis seal Juri kaendelas?

Kirves Juri kaendelas.

Mis sääl kirve lava pääl?

Laast sääl kirve lava pääl.

Mis sest laastust raiutakse?

Juri aita raiutakse.

Mis sääl Juri aida sees?

Kolm on noort neitsikest:

üks sääl ku’ub kuldavööda,

toine niub niitipaula,

kolmas nuttab noorda meesta [---] (H III 1, 777/8 (6) < ViruNigula (1889), osundatud ERlA e-variandi järgi). 


\section{Aado Lintrop}

Ilmselt ei märgi looja loog siin muud kui mingit paika väljaspool argimaailma, kuhu minnes on võimalik saada tuleviku kohta teateid. Harilikult selles tüübis kaare alt leitav kotkas võib olla jälg teadja linnukujulisest abivaimust (informaatorist). Konkreetses tekstis on aga jälle ühte liidetud mitu erinevat ennustusega seostuvat motiivi: kirves, laast ja kolm kuduvat neidu.

Selgelt ennustuslik on järgmine laulukatke, mis pärineb laulutüübist Vana kosilane, kus minategelane näeb endelist und:

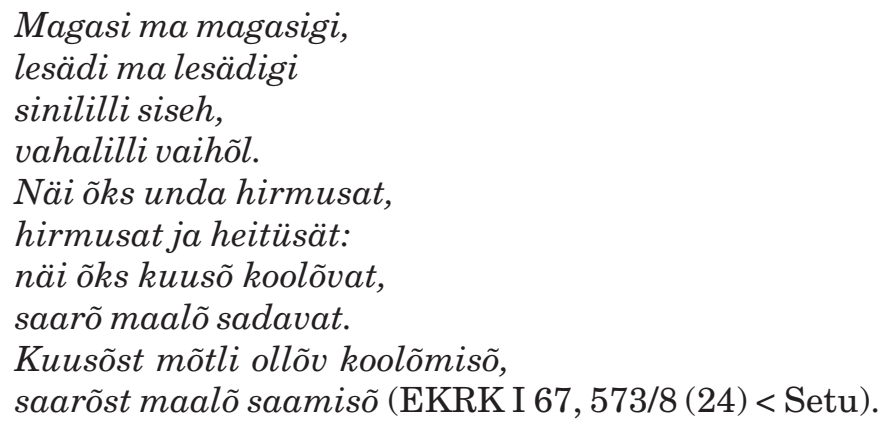

Kuigi talle kinnitatakse, et see ei tähenda surma, vaid kosijat, lõpeb lugu siiski surmaga. Lisaks sõja- ja surmamärkidele (mis muuseas on valdavad ka eestlaste tähistaevaga seotud ennetes) näitavad regilaulud eelkõige tulevase abikaasa ennustamist. Näiteks on järgmise Karula laulu algus tüüpilise ennustusviisi - häälte kuulamise - kirjeldus:

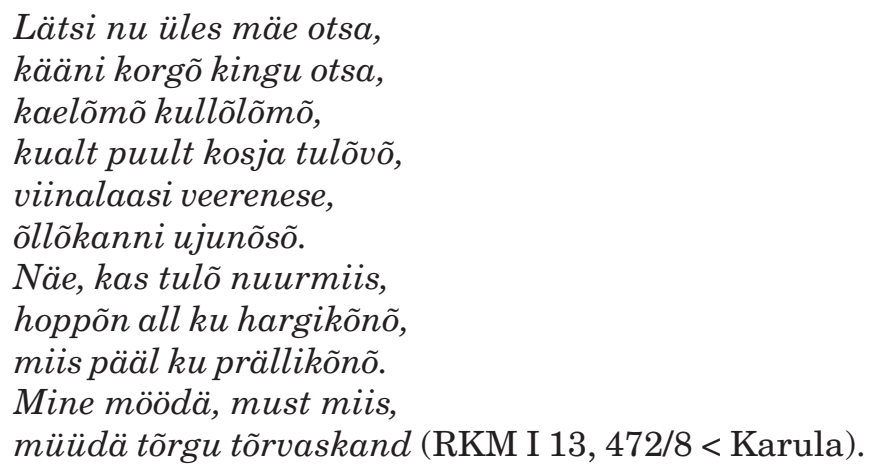

Sedalaadi ennustamised seostusid harilikult rahvakalendri tähtpäevadega. Eestis, Udmurtias ja mujalgi käidi tulevikku kuulamas eelkõige jõulude ajal. 
Aado Lintrop

\section{Ennustamine mitmesuguste esemete abil}

\section{a. Kirves}

Vast kõige selgemalt esineb kirvega ennustamise motiiv setu Imelise koja laulus.

Lätsi mõtsa minemähe, varikohe valamahe.

Lätsi hillä hellü pitemiä no minneh näie? Näie vaski varsakõsõ, näie hõpõ hõhvakõsõ, näie mõtsa minevätä, varikohe valavata, üle tii näi minevätäsiidi sarvilõ sibisi, vanik lehele valisi. Lätsi hillä hellü pite, saie tuuhu mõisahe, koh kota tettigi, vaski kota valõtigi. Kolq oll' meestä koa päällä, kolq oll' kirvõsta käellä, kolq kirja kirvõnna, raamaduq ravva päällä. Meesi lausi meelestäni, lausi meele poolõstani: "Näiokõnõ noorõkõnõ, tunnõt kirja kirvõhõ, raamatuta ravva päällä?” Näio lausi meelestäni: "Tunnõ-i kirja kirvõhõ, raamatuta ravva pääle; tunnõ ma kirja kangahe, raamatuta ravva pääle!” Näio kudi sinikangast, näio hiidi helläst langa (E, StK 22, 38/9 (31) < Setu). 
Aado Lintrop

Manside kohta on juba Bernát Munkácsi kirjutanud:

Kui keegi tahab, et talle ennustatakse, seob nõid nööri ennustamiskirve külge, võtab nööri keskelt kinni, loeb haldja kutsumise loitsu või arbub sõnatult. Kui ta kohtab haldja hinge, siis kirves liigub, kui ei kohta, siis ei liigu. Nii nagu haldjas talle ilmutab, nõnda ta räägib (Karjalainen 1918: 597).

Kirvega ennustada oskavat inimest on põhjamansid nimetanud pengeұum (kirvemees). Komi teadmamees on kirvest kasutanud nii:

Haigust või häda sümboliseeriv riidekompsuke riputati koos ikooniga puupaku sisse löödud kirve külge. Mõnikord riputati kirves koos kompsukesega ka leivalabida külge. Ennustamine toimus köögis ahjusuu ees. Tark luges nende pühakute nimesid, kes võisid abipalujat karistada. Kelle nimetamisel kompsuke liikus, sellele tuli ohver tuua (Gribova 1975: 104).

Muuseas mainib Karjalainen, et kirve asemel kasutasid obiugrilased ka nuga või veel meelsamini vana mõõka (Karjalainen 1918: 596). Nii kirves kui ka mõõk on ennustamisvahenditena väga levinud, mõõka on kasutanud näiteks tiibeti oraaklid, sardi (usbeki) šamaanid ja ka udmurdi teadjad. Esitatud näites on veel üks huvipakkuv detail: heli järgi minek. Siberi šamaanid on sageli väitnud, et orienteeruvad oma rännakutel (eriti tagasiteel) trummi või kellukese heli järgi.

\section{b. Mõõk}

Regilauludes esineb Mõõk merest sageli koos Harja otsimise motiiviga. Merest leitud mõõk sümboliseerib sõda ja surma. Selle motiivi puhul on siiski ehk olulisem mõõga leiukoht meri. Päikese kannul merre läinud kangelane, kelle eesmärgiks päeva suga (päikesekiirte võrdkuju) tagasi tuua, võtab ju tegelikult ette teekonna allilma, kus ta loomulikult kohtab surma.

\section{c. Laastud}

Järgmises põhjaranniku tekstis leiame kirve Venna sõjaloost, variandist, millesse on huvitaval kombel koondunud mitmed ennustusega seostatavad motiivid. 
Lähme Loojale loole, Marialle einamaale, Looja loogu võttemaie, Mariat kaarutamaie! Mis sa leidsid kaare alta? Leidsin tedre kaare alta. Mis seal tedre tiiva alla? Neiu tedre tiiva alla.

Mis seal neiu põlle alla?

Poeg on neiu põlle alla.

Mis seal poja vöö vahela?

Kerves poja vöö vahela.

Mis seal kerve nurga peale?

Laast on kerve nurga peale.

Mis sest laastust raiutakse?

Tuba neljanurgeline,

kamber kahekandiline,

aita viieviiruline,

lauda kuuekeeruline.

Mis seal tuas tehtanekse?

Sõjaleiba sõtkutasse, vainukakku vaalitasse.

Kesse sõtkub sõjaleivad,

kesse vaalib vainukakkud?

Õde sõtkub sõjaleivad (Haljala - VK 1989: 336).

Viimase teksti puhul ei ole tegemist ilmselt eelkirjeldatud kirve abil ennustamise viisiga, pigem on kirves vahend laastude löömiseks. Laastud aga on laialt levinud ennustamisvahendiks. Saaremaal usuti, et paadi kiilupuu tahumisel löödud esimese laastu langemise järgi saab ennustada aluse saatust.

Esimese laastu kukkumise viisi järgi oli [---] võimalik ennustada laeva saatust - kui laast kukub kummuli, ei kõlba see puu kiiluks, sest alus kummub meres (Naber 1995: 290).

Ilmselt on uskumus, et kummuli kukkuv ese ennustab halba, üsna universaalne. Näiteks ennustas idahandi šamaan lusikat visates: kummuli kukkunud lusikas oli märgiks, mis ei kinnitanud ta sõnu (ei-vastus; Karjalainen 1918: 588). Siberis on üldine arvamus, et kummuli kukkunud trumminui on halb enne. Astrid Tuisu väitel 
Aado Lintrop

esineb Suetuki küla eestlastel seoses maja ehitamisega uskumus, mille kohaselt tulevase maja piiridest väljapoole kukkuv laast ennustab seda, et jutud hakkavad majast välja kostma.

\section{d. Leib}

Eelmises tekstinäites esinenud vaenukakud ja sõjaleivad pole juhuslikud, neid kohtab samas kontekstis üsna rohkesti. Ent ka leib on ennustusvahendina kasutusel olnud:

Lozva alamjooksu elanikud [lõunamansid - A. L.] kasutavad selleks otstarbeks leiba: kaks inimest hoiavad tervet leiba pöialde peal ja üks ütleb: "Kui N. tuleb, keerab leib ennast päikesetõusu poole." Kui leib keerab, läheb väidetu täide (Karjalainen 1918: 596).

Udmurdi tark tuno pani värtnaga ennustades lauale ruudukujuliselt kaks leivatükki ja kaks sütt. Millisele neist targa käes rippuv värten lähenes, sellest tehti järeldused järeleküsitud asja suhtes (Holmberg 1914: 204).

\section{e. Taimed}

Regilauludes esinevad kaks taime samasuguses binaarses opositsioonis, mis valitseb leivatüki ja söe vahel, nimelt maagiline lemmeleht ehk leemeleht ja kooluhain. Olen üsna veendunud, et sümbolitena osutavad need ülaltoodud näites kirjeldatud udmurdi targa toimingute sarnasele informatsiooni hankimise viisile.

\section{f. Pühkmed (laastud)}

Ka järgmise Mis mees merest tõuseb tüübi varianti võib seostada laastude (või pühkmete) abil ennustamisega, mille eesmärgiks on oma tulevast meest näha.

Lähme merda pühkimaie, mere äärda äigamaie!

Pühime pühke'ed meresse, äigame laastud lainetesse. 
Aado Lintrop

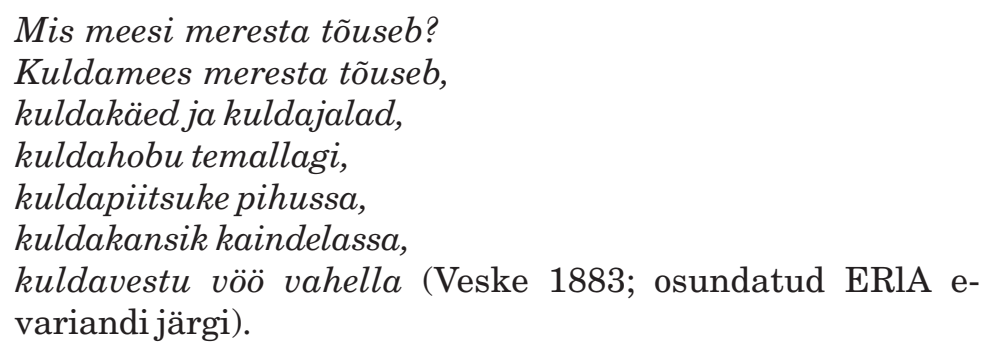

Võib-olla seostub eelnevate ridadega uskumus, et tulevase elukaaslase nägemiseks peab esimest korda noort kuud nähes maast midagi võtma ja une ajaks pea alla panema:

Kui esimest kord noore kuu näeb, siis tuleb säältsamast kohast, kus seisad, vasaku jala alt purusi võtta ja ihu põue panna, ning kui magama heidad, siis pea alla panna, siis nähja unes oma tulevast armukest (E 24810/1 (73) < Jämaja).

Siberi eestlaste juurest on pärit aga selline teade:

Võtsivad peergusid, kastsivad jõe ääres märjaks. Panivad põlema. Kellel kõige enne akkab see põlema, see märg laast, see saab kõige enne mehele. Tikuga tõmmasime tuld (RKM II 447, 409/10 (8) < Krasnojarski krai, Ülem-Suetuki k).

\section{g. Sõlg ja/või hõbeehe ja/või vääriskivi}

Laulutüübis Uppunud vend esineb järgmine motiiv:

Võtsin sõle rinnasta,

lehe laia kaelasta;

panin sõle sõudema,

lehe laia lendama:

"Sõua, sõlge, lenda, lehte!" (Haljala - ERl 1926: 203)

või

Panin sõle sõudemaie,

lehe laia lendamaie,

kive kulla kirkamaie:

"Sõua, sõlge, lenna, lehte,

kirka, kulla kivekene!” (Jõhvi - ERl 1926: 201). 
Aado Lintrop

Värsid viitavad selgesti, et venna saatuse selgitamine käis hõbeesemete abil, mis oli üldlevinud ennustamisviis, vrd kas või udmurdi targa ütlusega:

Harilikult vaatan ma hõbeda peale ja kui hõbe muutub tuhmiks, tähendab see, et haige on kurja silma poolt kaetatud, aga kui ta on kaetatud, näen kahte teed, üks tähendab kaotust - loom, mis tuleb ohverdada, näitab oma pead; kui aga on tarvis surnuid mälestada, ilmuvad küünal ja lehm (Bogajevski 1890: 124-125).

Sõle sõudma panek võib muidugi tähendada ennustamist pendeldava või ringe sooritava sõle abil (nagu näiteks tänapäeval sõrmusega ennustatakse).

\section{h. Sõrmus}

Laulutüübis Neli neidu (Luust sõrmus, Meri meie õue all) on sõle peal või sees sõrmus, milles neli kuduvat neidu, kes selgelt seotud inimsaatuse määramisega:

Mis seel sormukse sisessa?

Neli noorta neitsikesta:

üks seel kuab kuldavööda,

teine vaalib vaskivööda,

kolmas poomib pollesida,

neljas nutab noorta miesta (Haljala - VK 1989: 172).

Mõnikord mainitakse, et sõrmus ise on tehtud sõjameeste sõrmeluist. Sõrmusega ennustamine on populaarne tänapäevalgi. Huvi võib aga pakkuda 18. sajandist pärinev teade jakuudi šamaanist, kes sel kombel ennustas:

Šamaan võtab sõrmuse või mündi ja hoiab seda eri suundades liigutades ja nagu silmitsedes küsitletava peo kohal ning pärast ennustab tulevikku (Mihhailovski 1892: 82 Johann Georg Gmelini järgi).

Mida öelda selleks, et purustada eelneva jutu peale ehk tärganud illusioone? Hoolimata sellest, et esitasin mõned regilaulumotiivid, mis võivad olla tähenduslikud seoses kadunud usundikompleksi 
jäänustega, ei näe ma oma käsitluses võimalust regilaulude universaalseks tõlgendamiseks. Maagia ja ennustamine on vaid üks võimalik suund või tee motiivide labürindis. Regilaulude motiivid pole maagiliste toimingute täpsed kirjeldused. Nad pole ka ennustusviiside esitlemised. Peame meeles pidama, et eelkõige on nad poeetilised väljendused ning need tähendused, mis neil on eesti regilaulude "sümbolite metsas" - või sobiks paremini öelda "metafooride põllul", - on hoopis teised.

\section{Kommentaar}

${ }^{1}$ Nganassaanid tõstsid kojakattesse mähitud või kirstu pandud surnu nartale ja sõidutasid matusepaika, kuhu narta ühes koormaga maha jäeti.

\section{Rahvaluulekogud}

\section{Eesti Rahvaluule Arhiiv}

EKRK - Eesti kirjanduse ja rahvaluule kateedri kogu.

E - M. J. Eiseni rahvaluulekogu, 1880-1934 ja mõned varasemad tekstid. E, StK - M. J. Eiseni stipendiaatide rahvaluulekogu, 1921-1927.

RKM - Eesti TA Fr. R. Kreutzwaldi nim (Riikliku) Kirjandusmuuseumi (nüüd Eesti Kirjandusmuuseumi) rahvaluule osakonna rahvaluulekogu, 1945-1995.

\section{Kirjandus}

Arukask, Madis 1998. "Venna sõjalugu” vormeliteooria valguses ning setu lüroeepika ruumisüsteemis. Magistritöö. Tartu Ülikool. Eesti ja võrdleva rahvaluule õppetool. Tartu.

Bogajevski 1890 = Богаевский, П. М. Очерки религиозных представлений удмуртов. Этнографическое обозрение $1,2,4$. Москва.

Croce, Benedetto 1998. Esteetika kui väljendusteadus ja üldlingvistika: Teooria ja ajalugu. Tartu: Ilmamaa.

ERl 1926 = Eesti rahvalaulud Dr. Jakob Hurda ja teiste kogudest I. Eesti Kirjanduse Seltsi Toimetused 21. Tartu. 


\section{Aado Lintrop}

ERlA 1969-1974 = Tedre, Ülo (toim). Eesti rahvalaulud: Antoloogia I-IV. Tallinn: Eesti Raamat. Elektrooniline variant: Eesti rahvalaulud: Antoloogia (http://haldjas.folklore.ee/laulud/erla/index.html - 10. juuli 2003).

Gribova 1975 = Грибова, Любовь. Пермский звериный стиль: Проблемы семантики. Москва: Наука.

Holmberg, Uno [Harva, Uno] 1914. Permalaisten uskonto. Suomensuvun uskonnot IV. Porvoo: WSOY.

Karjalainen, Kustaa Fredrik 1918. Jugralaisten uskonto: [Jugrernas religion]. Suomensuvun uskonnot III. Porvoo: Söderström.

Mihhailovski 1892 = Михайловский, Виктор. Шаманство: Сравнительноэтнографические очерки. Известия Общества любителей естествознания, антропологии и этнографии LXXV. Москва.

Naber, Reet 1995. Õnnelikku merereisi! Uskumustest seoses laevaehitusega. Mall Hiiemäe \& Mare Kõiva (toim). Rahvausund tänapäeval. Tartu: Eesti TA Eesti Keele Instituut \& Eesti TA Eesti Kirjandusmuuseum, lk 285-295.

Popov 1984 = Попов, Аидрей. Нганасаны: Социальное устройство и верования. Ленинград: Наука.

SL 1904 = Hurt, Jakob. Setukeste laulud I: Pihkva-Eestlaste vanad rahvalaulud, ühes Räpinä ja Vastseliina lauludega. Monumenta Estoniae antiquae I, Carmina popularia 1. Suomalaisen Kirjallisuuden Seuran Toimituksia 104. Helsinki: Soome Kirjanduse Selts.

Veske, Mihkel 1883. Eesti rahvalaulud II. Eesti kirjavara 2. Tartu: Schnakenburg.

VK 1989 = Laugaste, Eduard. Haljala regilaulud. Vana Kannel 6:1. Eesti regilaulud $=$ Estonum carmina popularia. Tallinn: Eesti Raamat. 